University of Nebraska - Lincoln

DigitalCommons@University of Nebraska - Lincoln

1999

\title{
Temperature Trends of the U.S. Historical Climatology Network Based on Satellite-Designated Land Use/Land Cover
}

\author{
Kevin P. Gallo \\ National Climatic Data Center, Kevin.P.Gallo@noaa.gov \\ Timothy W. Owen \\ National Climatic Data Center \\ David R. Easterling \\ National Climatic Data Center \\ Paul F. Jamason \\ University of California
}

Follow this and additional works at: https://digitalcommons.unl.edu/natrespapers

Part of the Natural Resources and Conservation Commons

Gallo, Kevin P.; Owen, Timothy W.; Easterling, David R.; and Jamason, Paul F., "Temperature Trends of the U.S. Historical Climatology Network Based on Satellite-Designated Land Use/Land Cover" (1999). Papers in Natural Resources. 192.

https://digitalcommons.unl.edu/natrespapers/192

This Article is brought to you for free and open access by the Natural Resources, School of at DigitalCommons@University of Nebraska - Lincoln. It has been accepted for inclusion in Papers in Natural Resources by an authorized administrator of DigitalCommons@University of Nebraska - Lincoln. 


\title{
Temperature Trends of the U.S. Historical Climatology Network Based on Satellite-Designated Land Use/Land Cover
}

\author{
KeVIN P. Gallo \\ Office of Research and Applications, NOAA/NESDIS, Washington, D.C. \\ Timothy W. Owen AND DAvid R. EAsterling \\ National Climatic Data Center, Asheville, North Carolina \\ PAUL F. JAMASON \\ Scripps Institution of Oceanography, University of California, San Diego, La Jolla, California
}

18 February 1998 and 16 June 1998

\begin{abstract}
The 1221 weather observation stations that compose the U.S. Historical Climatology Network were designated as either urban, suburban, or rural based on data from the Defense Meteorological Satellite Program Operational Linescan System (OLS). The designations were based on local and regional samples of the OLS data around the stations (OLS method). Trends in monthly maximum and minimum temperature and the diurnal temperature range (DTR) were determined for the 1950-96 interval for each of three land use/land cover (LULC) designations. The temperature trends for the OLS-derived designations of LULC were compared to similarly designated LULC based on (i) map- (Operational Navigation Charts) and population-based estimates of LULC (ONCP method), and (ii) LULC designations that resulted from of a survey of the network station operators. Although differences were not statistically significant, the DTR trends (degrees Celsius per 100 years) did differ between the LULC classes defined by the OLS method, from -0.41 for the rural stations to -0.86 for the urban stations. Trends also differed, although not significantly, between the methods used to define an LULC class, such that the trends in rural DTR varied from -0.41 for the OLS defined stations to -0.67 for the ONCP defined stations. Although the trends between classes were not significantly different, they do present some contrasts that might confound the interpretation of temperature trends when the local and regional environments associated with the analyzed stations are not considered. The general (urban, suburban, or rural) LULC associated with surface observation stations appears to be one of the factors that can influence the trends observed in temperatures and thus should be considered in the analysis and interpretation of temperature trends.
\end{abstract}

\section{Introduction}

The influence of land use/land cover (LULC) on several meteorological variables has been well documented (e.g., Landsberg 1981; Kukla et al. 1986; Karl et al. 1988; Changnon 1992; Gallo et al. 1993; Gallo et al. 1996). Gallo et al. (1996) suggested that the LULC associated with climate observation stations needed to be periodically monitored. Gallo et al. (1996) speculated that the transition of the LULC from predominantly rural to a more urban setting can have an impact on the trends in temperature (specifically a decrease in the di-

Corresponding author address: Kevin P. Gallo, National Climatic Data Center, 151 Patton Ave., Asheville, NC 28801.

E-mail: kgallo@nesdis.noaa.gov urnal temperature range) similar to that which would be expected under an enhanced greenhouse warming scenario. Thus, the LULC influences on temperatures, as opposed to greenhouse warming influences, need to be clearly differentiated.

Imhoff et al. (1997a) and Imhoff et al. (1997b) have successfully used Defense Meteorological Satellite Program Operational Linescan System (OLS) data (Elvidge et al. 1997a) acquired at night to identify "urban areas." The OLS-based estimates of "urban" area were within $5 \%$ of the area defined by the 1990 U.S. census for the conterminous United States (Imhoff et al. 1997b). The OLS radiometer includes two spectral bands. The visible band ranges from 0.5 to $0.9 \mu \mathrm{m}$. The sensitivity of the radiometer to light at night is four orders of magnitude greater than that of the National Oceanic and Atmospheric Administration (NOAA) Advanced Very High 
TABLE 1. Decision logic of the OLS and ONCP methodologies for designation of the general LULC associated with a climate observation station.

\begin{tabular}{|c|c|c|c|}
\hline Local sample & & Regional sample & Result \\
\hline \multicolumn{4}{|l|}{ OLS } \\
\hline NONE Urban, (predominantly rural) & AND & Urban and suburban grid cells $<25 \%$ & Rural \\
\hline NONE Urban (predominantly suburban) & OR & $25 \% \leq$ urban and suburban $<50 \%$ & Suburban \\
\hline ANY Urban & OR & Urban and suburban $\geq 50 \%$ & Urban \\
\hline Population & & & Result \\
\hline \multicolumn{4}{|l|}{$\mathrm{ONCP}$} \\
\hline Population $<10000$ & & & Rural \\
\hline $10000 \leq$ population $\leq 50000$ & & & Small town (suburban) \\
\hline Population > 50000 & & & Urban \\
\hline
\end{tabular}

Resolution Radiometer (AVHRR) or Landsat-TM (Elvidge et al. 1997a).

The objectives of this study were to apply a satellitebased designation of general LULC to the over 1200 U.S. Historical Climatology Network (HCN) stations and determine the temperature trends associated with these general LULC classes. The results of the satellitebased designations of LULC were compared to two other designations of LULC.

\section{Methodology}

The U.S. HCN serial temperature dataset (Easterling et al. 1996) is updated periodically and includes monthly temperature data that have been adjusted to remove biases caused by changes in the time of observation, changes in instruments, movement of weather stations, and urbanization. The HCN dataset is available in several versions that include no adjustments, one or more of the adjustments, or all of the adjustments. The data utilized in this study included adjustments for changes in time of observation, changes in instruments, and movement of weather stations. The temperature variables examined in this study included minimum and maximum temperature and the diurnal temperature range $(\mathrm{DTR}=$ maximum - minimum temperature $)$.

Owen et al. (1998) developed a methodology for use of OLS data to objectively define climate observation stations as urban, suburban, or rural. Briefly, the OLS data (acquired during 1994 and 1995) represent the frequency that cloud-free lights were detected for each 1$\mathrm{km}$ grid cell relative to the total number of cloud-free observations of the grid cell (Elvidge et al. 1997a). Each $1-\mathrm{km}$ grid cell in the conterminous United States was designated as urban, suburban, or rural, based on two thresholds. The OLS urban threshold was suggested by Imhoff et al. (1997a) and Imhoff et al. (1997b), and a rural OLS threshold was established by Owen et al. (1998) through the use of gridded U.S. census housing density data.

The methodology to determine if a climate station was urban, suburban, or rural included the analysis of local and regional samples of the categorized $1 \mathrm{~km}^{2}$ grid cells around the stations. Local and regional samples of the grid cells that surrounded the stations were made, which included $3 \times 3 \mathrm{~km}^{2}$ and $21 \times 21 \mathrm{~km}^{2}$ samples, respectively. The decision logic used to determine if a station was urban, suburban, or rural was based on the classification of the individual grid cells within the local and regional samples associated with each station, as seen in Table 1. A progressive decision logic was applied to each of the $1221 \mathrm{HCN}$ stations. First, station samples were tested to see if they met the criteria for a rural designation. Station samples not meeting these conditions were then tested for the suburban designation. Subsequently, the remaining unclassified stations were designated as urban. Thus, a station with any urban grid cells located in the local sample would be immediately classified as urban. A station with no urban grid cells observed in the local sample and a regional sample with less than $25 \%$ urban and suburban grid cells would then be evaluated by the local sample criteria (predominance of rural or suburban grid cells) included in Table 1 to determine if it was a suburban or rural station.

Figure 1 displays the results of the OLS methodology for the Baltimore, Maryland, to Washington, D.C., region of the United States. A water mask, not used in the analysis, was overlaid on the OLS data to identify the Chesapeake Bay and other major water bodies in the region. The HCN stations are overlayed on the OLS data and are designated rural, suburban, and urban as a result of the logic displayed in Table 1. The station designated rural at the eastern (right) edge of the figure presents a good example of the decision logic in Table 1. The station clearly has nearby grid cells defined as suburban. In fact, four of the nine grid cells that compose the local $(3 \mathrm{~km} \times 3 \mathrm{~km})$ sample are suburban. However, as the local sample is predominantly rural (five of the nine grid cells) and the regional sample includes less than $25 \%$ suburban grid cells, the station is designated as rural.

The results of the OLS methodology to designate station LULC were then compared to two other designations of LULC associated with the HCN stations. One of the methods for LULC designation of the stations (Peterson and Vose 1997) utilized maps and population data [Operational Navigation Charts and Population (ONCP) methodology]. Briefly, the ONCP methodology 


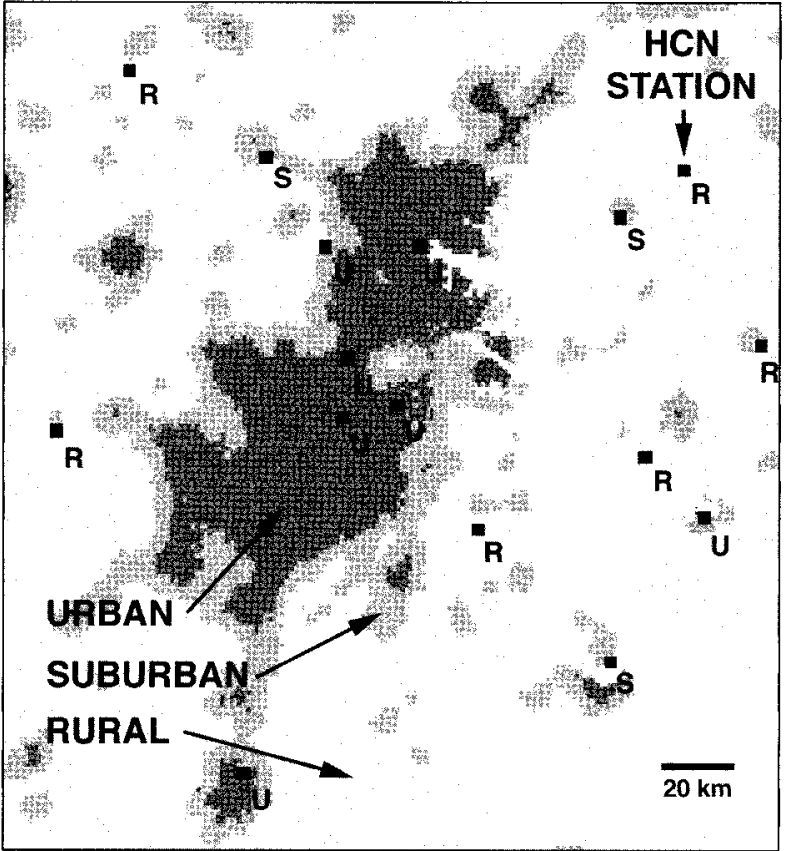

FIG. 1. U.S. HCN stations within the Baltimore, MD-Washington, DC, region as overlaid on the OLS-designated rural, suburban, and urban areas. Station designations as a result of the OLS-based methodology are indicated $(\mathrm{R}=$ rural, $\mathrm{S}=$ suburban, and $\mathrm{U}=$ urban). The Chesapeake Bay and other major water bodies are identified as white.

uses Defense Mapping Agency ONCs that designate the location of urban areas. Station location on the chart determined whether a station was in an urban or rural area. Population values were also considered as described in Table 1. The "small town" designation of Peterson and Vose (1997) was considered as "suburban" in this study.

A second LULC designation used for comparison, designated as HCNSVY, was derived from a survey of the observers associated with each of the $\mathrm{HCN}$ stations (Gallo et al. 1996). The observers were requested to estimate the predominant LULC (from nine choices) within 100-, 1000-, and $10000-\mathrm{m}$ radii of the station location. The nine classes included in the survey were condensed to the three used in this analysis (rural, suburban, and urban) based on the results of Gallo et al. (1996).

The station temperature data were gridded on a $5^{\circ} \times$ $5^{\circ}$ basis with inhouse software, and anomalies were computed from the base interval of 1961-90. The data were gridded to assure that the temperature trends were not dominated by regions with a relatively large number of stations. Additionally, each station was required to have a minimum of $25 \mathrm{yr}$ of data within the 1950-96 interval for inclusion in the analysis.

Trends in the anomalies of gridded monthly minimum and maximum temperatures and the DTR were examined for stations based on their LULC designations as
TABLE 2. The major land use/land cover categories ( $\mathrm{r}=$ rural, $\mathrm{s}$ = suburban, $\mathrm{u}=$ urban, nonu $=$ nonurban $)$, number of stations designated within that category, and trends $\left[{ }^{\circ} \mathrm{C}(100 \mathrm{yr})^{-1}\right]$ in the DTR, maximum, and minimum temperatures for the 1950-96 interval.

\begin{tabular}{lrlll}
\hline \hline & $\mathrm{n}$ & \multicolumn{1}{c}{ DTR } & Max & Min \\
\hline All stations & 1221 & $-0.72^{* *}$ & 0.30 & $0.98^{* *}$ \\
HCNSVYr & 307 & $-0.63^{*}$ & 0.47 & $1.02^{* *}$ \\
OLSr & 292 & -0.41 & 0.12 & 0.56 \\
ONCPr & 820 & $-0.67^{*}$ & 0.20 & $0.84^{* *}$ \\
HCNSVYs & 377 & $-0.66^{*}$ & 0.22 & $0.86^{* *}$ \\
OLSs & 465 & $-0.81^{* *}$ & 0.24 & $1.02^{* *}$ \\
ONCPs & 288 & $-0.66^{*}$ & 0.34 & $0.93^{* *}$ \\
HCNSVYu & 515 & $-0.82^{* *}$ & 0.30 & $1.06^{* *}$ \\
OLSu & 464 & $-0.86^{* *}$ & 0.38 & $1.22^{* *}$ \\
ONCPu & 113 & $-0.74^{* *}$ & 0.69 & $1.42^{* *}$ \\
HCNSVYnonu & 684 & $-0.62^{*}$ & 0.31 & $0.90^{* *}$ \\
OLSnonu & 757 & $-0.63^{*}$ & 0.24 & $0.83^{* *}$ \\
ONCPnonu & 1108 & $-0.66^{* *}$ & 0.28 & $0.90^{* *}$ \\
\hline
\end{tabular}

$*$ Trends are significantly different from 0.0 at $\alpha=0.1$.

$* *$ Trends are significantly different from 0.0 at $\alpha=0.05$.

urban, suburban, or rural, determined by the OLS, ONCP, and HCNSVY methodologies. The trends were also determined for the nonurban (rural or suburban) consolidation of stations.

The significance of the temperature trends (significantly different from 0.0 ) was based on a $t$ statistic in the GLM procedure (SAS 1988). The observed temperature trends for the stations were also analyzed for significant differences due to station LULC designation within a specific methodology (e.g., trends in the urban stations as defined by the OLS, ONCP, or HCNSVY methodologies). Analysis of the differences in the temperature trends between LULC designations included comparisons of the error sum of squares associated with the regression equations derived to determine the temperature trends (Neter and Wasserman 1974). Trends were also analyzed for significant differences between LULC designations within a single designation methodology (e.g., trends in the rural compared to suburban and urban stations as designated by the OLS methodology).

\section{Results and discussion}

Inherent differences exist between the methods for designating a climate observation station as urban, rural, suburban (OLS and HCNSVY methodologies), or small town (ONCP). These differences are demonstrated in the varied range in the number of stations designated as rural, from the ONCP value of 820 to the OLS value of 292 (Table 2). The number of urban stations varied from an ONCP value of 113 to an HCNSVY value of 515 . The number of nonurban (either rural or small town for ONCP, or rural or suburban for OLS or HCNSVY designations) varies from an ONCP-designated 1108 to an HCNSVY-designated 684. Although the number of stations per LULC class varied, the spatial coverage of 
the United States as represented by the $5^{\circ} \times 5^{\circ}$ grid cells was usually greater than $85 \%$. The differences in the trends observed between the methods may potentially be related to (i) true differences in the LULC as defined for the stations and (ii) the number and spatial distribution of the stations associated with a given class.

Additionally, included in this analysis is the assumption that the three designations provide value-added insight into retrospective LULC conditions. Each of the three methods for designation of the LULC classes, however, is a "snapshot" in time of the LULC. The time frame associated with each of the methods for designation of LULC does differ. The HCNSVY classes are based on a survey conducted in 1990, the OLS classes are based on data acquired during 1994 and 1995, and the ONCP classes are based on maps compiled in the 1970s and currently available population data.

Within this analysis, rural-designated stations are assumed to have been rural throughout the period of trend assessment. Urban and suburban stations may or may not have maintained their LULC character for the period of trend assessment. Some stations currently designated as urban by the three methodologies above may have been suburban or even rural in 1950. Similarly, given population trends and settlement patterns in the United States since 1950, some of the stations currently designated as suburban were likely rural stations in 1950. Thus, changes in a station's LULC over time may confound the use of the temperature data acquired at the station for trend analysis.

The trends in the maximum and minimum temperature and DTR associated with the HCNSVY, ONCP, and OLS LULC designated classes (Table 2) are generally similar to previous analyses of temperature trends for U.S. stations (Karl et al. 1993). Generally there is a decrease in DTR, nonsignificant changes in the maximum temperature, and increasing minimum temperature. The trends associated with the maximum temperatures (Table 2) were not significantly different (from a value of 0.0 ) for any of the LULC designations and thus were not evaluated further.

The trends in minimum temperature and DTR were examined by LULC for the HCNSVY, OLS, or ONCP designations. Although the trends differed within each of the three LULC designations, these differences were not significant $(\alpha=0.1)$. Thus even the DTR differences within the rural LULC class that ranged from -0.41 (for the OLS designations) to -0.67 (ONCP designation) were not significant.

Similarly, the trends in minimum temperature and DTR were examined by method of class designation for the rural, suburban, and urban classes. There were no significant $(\alpha=0.1)$ differences in the trends observed between LULC classes within any of the methods used to designate the LULC class. Thus, even the difference in minimum temperature trends between the ONCP-designated rural (0.84) and urban (1.42) classes was not significant.
Although the trends between classes were not significantly different, they do present some contrasts that might confound the interpretation of temperature trends when the local and regional environments associated with the analyzed stations are not considered. The OLSdesignated rural stations, for example, exhibit a DTR trend of -0.41 while the urban stations exhibit a trend of -0.86 .

Generally, a station designated as urban or suburban that was rural at one time during the 1950-96 interval would be expected to have a greater decrease in the observed diurnal temperature range over time when compared to a rural station free of urban influences. Gallo et al. (1996) found that the LULC associated with urban stations resulted in DTRs that were significantly lower than those of rural stations. As the LULC around a station changes from rural to urban over time, the DTR will likely decrease due to this transition, in addition to any influences due to potential greenhouse warming. Urban stations that have experienced little change in their surrounding LULC characteristics over time, however, might be expected to display DTR trends that are less negative than those stations that have recently become urban or are in transition to becoming urban.

The DTRs associated with the urban classes defined in this study generally have greater decreases in the DTR compared to the suburban or rural classes. A noteworthy exception is the suburban class as designated by the OLS method, which has a decrease in DTR $(-0.81)$ nearly as great as the urban class $(-0.86)$. This may be due to the OLS definition of suburban (Table 1), which could be expected to correspond to stations that are in a transition from rural to urban. These stations might be expected to experience the greatest change in DTR as their temperatures shift from a nonurban to urban regime. The difference between the trends in the DTR observed for all stations $(-0.72)$ is reduced slightly when the HCNSVY $(-0.62)$, OLS $(-0.63)$, or ONCP $(-0.66)$ designated nonurban (rural or suburban) stations are utilized.

The results indicate that the trends observed in minimum temperature and DTR differ with LULC, although not significantly. Within an LULC class the trends in minimum temperature and DTR also differ (although not significantly) based on the method used for designating stations as urban, rural, or suburban.

\section{Summary}

The general (urban, suburban, or rural) land use/land cover (LULC) associated with surface observation stations can influence the trends observed in temperature. The designation of a station as rural, urban, or suburban (potentially in transition from rural to urban) can influence the results of analyses often used for detection of changes in the regional and global climate. The stations designated in this analysis were assumed to be constant 
throughout the interval of study. While this assumption is likely valid for rural stations (i.e., a station rural in the 1990s was likely rural in the 1950s), it may not be valid for some of the suburban or urban stations. Thus, the general categories of LULC at a station, as well as the changes in these designations over time, may be important considerations. Periodic assessment of these general designations of LULC should be encouraged on a global basis. The satellite-based LULC designations utilized within this study, which relied on the anthropogenic visible light emitted from the earth's surface, resulted in temperature trends that were generally consistent with two other designations of LULC. The satellite-based methodology, while potentially applicable on a global basis, will likely have to be refined to account for regional or country variability (Elvidge et al. 1997b).

Acknowledgments. This study was partially supported by the NOAA Office of Global Programs and NASA.

\section{REFERENCES}

Changnon, S. A., 1992: Inadvertent weather modification in urban areas: Lessons for global climate change. Bull. Amer. Meteor. Soc., 73, 619-627.

Easterling, D. R., T. R. Karl, E. H. Mason, P. Y. Hughes, and D. P. Bowman, 1996: United States Historical Climatology Network (U.S. HCN) monthly temperature and precipitation data. ORNL/ CDIAC-87, NDP-019/R3, Carbon Dioxide Information Analysis Center, Oak Ridge National Laboratory, Oak Ridge, TN, 280 pp. [Available from National Technical Information Service, 5285 Port Royal Rd., Springfield, VA 22161.]

Elvidge, C. D., K. E. Baugh, E. A. Kihn, H. W. Kroehl, and E. R. Davis, 1997a: Mapping city lights with nighttime data from the
DMSP operational linescan system. Photogramm. Eng. Remote Sens., 63, 727-734.

- - - and C. W. Davis, 1997b: Relation between satellite observed visible-near infrared emissions, population, economic activity and electric power consumption. Int. J. Remote Sens., 18, 1373-1379.

Gallo, K. P., A. L. McNab, T. R. Karl, J. F. Brown, J. J. Hood, and J. D. Tarpley, 1993: The use of NOAA AVHRR data for assessment of the urban heat island effect. J. Appl. Meteor., 32, 899-908.

- D. R. Easterling, and T. C. Peterson, 1996: The influence of land use/land cover on climatological values of the diurnal temperature range. J. Climate, 9, 2941-2944.

Imhoff, M. L., W. T. Lawrence, C. D. Elvidge, T. Paul, E. Levine, M. V. Privalsky, and V. Brown, 1997a: Using nighttime DMSP/ OLS images of city lights to estimate the impact of urban land use on soil resources in the United States. Remote Sens. Environ., 59, 105-117.

,-- D. C. Stutzer, and C. D. Elvidge, 1997b: A technique for using composite DMSP/OLS "city lights" satellite data to map urban area. Remote Sens. Environ., 61, 361-370.

Karl, T. R., H. F. Diaz, and G. Kukla, 1988: Urbanization: Its detection and effect in the United States climate record. J. Climate, 1, 1099-1123.

_ and Coauthors, 1993: A new perspective on recent global warming: Asymmetric trends of daily maximum and minimum temperature. Bull. Amer. Meteor. Soc., 74, 1007-1023.

Kukla, G., J. Gavin, and T. R. Karl, 1986: Urban warming. J. Climate Appl. Meteor., 25, 1265-1270.

Landsberg, H. E., 1981: The Urban Climate. Academic Press, 275 pp.

Neter, J., and W. Wasserman, 1974: Applied Linear Statistical Models. Richard D. Irwin, Inc., 841 pp.

Owen, T. W., K. P. Gallo, C. D. Elvidge, and K. E. Baugh, 1998: Using DMSP-OLS light frequency data to categorize urban environments associated with U.S. climate observing stations. Int. J. Remote Sens., 19, 3451-3456.

Peterson, T. C., and R. S. Vose, 1997: An overview of the global historical climatology network temperature database. Bull. Amer. Meteor. Soc., 78, 2837-2849.

SAS, 1988: SAS/STAT User's guide release 6.03 edition. SAS Institute Inc., 1028 pp. [Available from SAS Institute, Inc., SAS Circle, Box 8000, Cary, NC 27512.] 